\title{
Reflections on Meaningfulness and its Social Relevance
}

Nicole Note

\section{Introduction}

$\mathrm{P}$ hilosophers who write about the meaning of life are few nowadays. The subject has lost its attractiveness. Perceived from a viewpoint of logical positivism or language philosophy, the whole issue of meaningfulness seems rather pointless. It is often considered to be related to metaphysics, making it less suitable for philosophical inquiry. The topic of meaningfulness seems too intangible. Indeed, the few philosophers that have embarked on examining meaningfulness have proven to be well aware of the challenges this poses. At times they acknowledge that the more they concentrate on the subject, the more it seems to fall apart into unintelligible pieces about which nothing of philosophical value can be said. ${ }^{1}$

And yet, on a personal level, the questions of why people live and how to live a meaningful life are so central to humanity that at one point it will inevitably emerge in anybody's life. The modern condition is such that people spend most of their days doing routine activities, hurrying from one place to another. However, this routine is interrupted, at unexpected or expected moments, by familiar and personal milestones: a birth or death in the family, a new job, or simply somebody turning thirty, forty or fifty. Such moments may inspire people to reflect on their life and make them see it from a different viewpoint, one that encompasses a larger, external reality.

The question of a meaningful life and its implications is something that everyone will have to face one way or another. This requires a philosophical examination to widen and deepen understanding. Although the answers may be incomplete, raising questions and facing issues may provide a firm grasp on its implications.

The following parts will first summarise the existing viewpoints on meaningfulness: the religious one; the current that believes meaningfulness is a matter of choice and preferences; and the third that takes 'objective values that are appealing' as a standard. It is mainly the latter viewpoint that is of interest to our discussion. It makes it possible to bring back insights into

1 An overview of the literature on meaningfulness see E. D. Klemke and Steven M. Cahn, The meaning of life. A Reader (USA: Oxford University Press, 2008), in Philosophical Papers, 34:3 (2005) and more recently in The Monist, 93:1(2010). 
meaningfulness that have become obscured over time, such as the passivity of responding to something and being touched by something. It also offers opportunities to expand on these themes.

\section{Different Approaches to Meaningfulness}

One of the philosophers associating meaningfulness with religion is John Cottingham. In his book On the Meaning of Life, ${ }^{2}$ he declares that the scientific assertions about the origin of man, i.e. that man was made of star dust, are considered mere facts. Yet these assertions subtly but undeniably influence man's view of himself, the world as well as the meaning of his existence. Scientific findings make the world appear to him in mechanistic terms and hence as predominantly irrational, blind, lifeless and devoid of meaning. As a result, the world strikes man as a place of arbitrariness where nothing really matters. Cottingham counterbalances this disenchanting wave of scientific 'facts' with religion. To him, religious discourses grope towards meanings that are beyond the framework of methodical knowledge. They reach beyond the strictly knowable — but not beyond the thinkable — and aim to place human life within a context of significance and meaning. Even though this richness cannot be fully captured in scientific language, it can still be made manifest or disclosed. Despite the lack of ultimate evidence, it can offer "the hope to find a home."3

Cottingham keenly argues in favour of the possibility of giving religion a place within the scientific model of evolution. His main drive stems from the assertion that without religion no deep meaning is possible. A religious view allows our life to be attuned to an order that is both creative and good. Hence, to Cottingham, a deep sense of meaningfulness is inherently related to ethics and religion. This is achieved when man finds himself within an eternal and ethical framework.

Without saying it in so many words, Cottingham seems to believe that without religion meaningfulness can only result in personal preferences and choices. Cottingham follows Nietzsche when he argues that, if religion is a fantasy, an illusion, a lost comfort, meaning will have to be found within, in man's own will. This means that the foundations of people's decisions and beliefs are to be found in their inner selves.

The perspective of meaning as being rooted in personal preference is very powerful especially today. It is intrinsically related to the idea of personal autonomy because of people's will, consciousness and their ability to provide meaning to the world. The preference logic, which has had a great influence on modern ideas on meaningfulness, is mainly inspired by the utilitarian way of thinking worked out, inter alia, in the philosophical liberalism of John Steward Mill. ${ }^{4}$ It has since been reflected in many '-isms', such as libertarianism,

\footnotetext{
${ }^{2}$ John Cottingham, On the Meaning of Life (London: Routledge, 2003).

3 Ibid., 16.

${ }^{4}$ John Stuart Mill, On Liberty (London: Longman, Roberts \& Green, 1869).
} 
relativism or postmodernism. The following brief incursion into political philosophy aims to shed light on its roots.

According to philosophical liberalism, it is a violation of people's fundamental interests to impose a specific view of what should be considered the good life. Freedom of choice is necessary to find out what is valuable in life-to form, examine and revise beliefs about value. It is assumed that people cannot be wrong in their choices; choices are arbitrary and cannot be rationally criticised. The main purpose in life is to be or to feel happy and it is up to every individual what that means. So the question of what people should desire in general terms is not deemed legitimate. On the contrary, freedom of choice and different conceptions of the good are presumed to lead to cultural richness and to further individual autonomy, precisely because of the oppositional character of some of these. According to this perception, choice and meaning come from within man, for liberal philosophy insists that people have an ability to detach themselves from any particular social practice or context and that no particular practice has any authority that is beyond individual judgement and rejection.

The discussion has lost some of its edge, thanks to authors such as Charles Taylor ${ }^{5}$ and Will Kymlicka. ${ }^{6}$ They have shown that preferences and choices are never really 'pure' from within. People are inherently embedded in discursive and social contexts which influence their underlying ontological assumptions, their self-understanding, their 'choices' of what they do and do not consider meaningful. Liberal philosophy is no exception to this: it cannot free itself from a framework. Indeed, both Taylor and Kymlicka have brought to the fore some of the implicit elementary liberal assumptions. These include the deeply rooted ideas of the need for individuals to explore their inner depths, the intrinsic autonomy and intrinsic moral worth of individuals, or the postulation that people are social by nature and will use their freedom to strive for common goods. ${ }^{7}$ In other words, the idea of choice proves also to be built up within a substantial discourse that orientates people's self-understanding in a more or les specific direction. It automatically yields an idea of how to act and of how to act meaningfully, providing a set of meanings to go by, to make choices in life, and for people to find out who they are and where they want to go.

Political philosophers have rightly pointed out that meaningfulness exists thanks to the appeal of cultural contexts. This brings us to the third approach in the realm of the philosophy of meaningfulness, the one that asserts that meaningfulness is brought about by contexts, works, values and the like that are appealing. One author who follows this line of thought is Susan

${ }^{5}$ Charles Taylor, Sources of the Self. The Making of Modern Identity (Cambridge: Cambridge University Press, 1989).

${ }^{6}$ Will Kymlicka, Contemporary Political Philosophy. An introduction (Oxford: Oxford University Press, 2002).

${ }^{7}$ Ibid., 217. 


\section{N. NOTE 141}

Wolf. ${ }^{8}$ In a more analytical manner, she states that meaning is found and given based on a complex relation between subjectivity and objectivity.

Wolf starts from the assumption that an individual cannot but perceive the world in terms of value. Meaningfulness seems an indispensable component of a good life, even if people usually do not express their lives and the world in these terms. Paradigmatic examples of what makes up meaningfulness are vocations, close relationships, worthwhile projects and commitments. Activities or relationships are not valuable because people perceive them as such. They appreciate them simply because they consider them meaningful. This insight is very close to another line in meaningfulness, elaborated by Nagel. According to this author, meaningfulness is not something humans can simply bring about in their lives, even though they have a certain ability to influence the process of meaning. Yet, whether acts, persons, and projects are meaningful or not can neither be simply chosen nor commanded by any individual. As Wolf states, it is rather a question of feeling, being called by vocations or drawn into relationships. ${ }^{9}$ People respond to and are attracted by something that they consider objectively appealing.

\section{Being Bound to the Horizon}

In this section the possibilities of this third 'line' of meaningfulness will be explored further, for it creates an opening towards 'passivity' without questioning autonomy. What do notions such as being called by something or drawn into something mean? These notions presuppose the perception of the evocative and the being touched. 'Evocative' and 'being touched' in relation to meaningfulness are easily associated with religion. A possible non-religious context of the evocative and the being touched has remained largely underexplored so far. Yet, it is of central importance to understand the genuine functioning of meaningfulness in people's lives. It offers the possibility to grasp why worthwhile projects, vocations and so on are appealing. As will be shown later, they can only be so if they have an elusive, evocative character.

Furthermore, once the idea of something that appeals is accepted, the opportunity arises to retrieve and fully grasp what Heidegger called the beingin-the-world. As Heidegger ${ }^{10}$ already pointed out, modern man fails to achieve a deep insight into his primordial relation with the world. Heidegger was referring to the 'fact' that people have always been and will always be a part of the world. They are not disengaged subjects but they are in a state of Dasein, of being-in-the-world, of inherent embeddedness. They have a broad range of

8 Susan Wolf, "Happiness and Meaning. Two aspects of the Good Life," in Social Philosophy and Policy, 14:1 (1997), 207-225.

9 Susan Wolf, "Meaning and Morality," in Proceedings of the Aristotelian Society, XCVII (1997), 299-315.

${ }^{10}$ Martin Heidegger, Being and Time, trans. by J. Stambaugh (Albany: State University of New York Press, 1996). 


\section{REFLECTIONS ON MEANINGFULNESS}

faculties at their disposal to approach the world-to gain access and relate to it - which include, but are by no means limited to, cognitive capacities.

However, due to the significant role that has been assigned to the sciences since the onset of the disenchantment wave, the influence of this cognitive capacity has increased. Society has now reached a point where other approaches to reality have simply ceased to be visible. They are not considered worthwhile anymore. As Cottingham rightly remarks, it is because of the prevalence of 'why' questions that certain answers predominate. ${ }^{11}$ 'Why' questions try to disclose the hidden world, and although they yield an ocean of knowledge, they can also cut off our access to other domains of thought and experience. It is thus that the perception of the surrounding world as a horizon has been lost. Disenchantment has had a flattening effect on man's perception of the world. ${ }^{12}$ In the disenchanted system of meaning that determines the relation with the world, the world is perceived as tangible, measurable and knowable — at least in principle.

Society has not been able to fully regain this potential experience of non-tangibility in an adapted way, notwithstanding many philosophical attempts and groundbreaking works. As we will try to show, the ability to see the world as that which surrounds man, more specifically as man's natural horizon, may contribute to retrieving a deeper sense of meaningfulness.

As stated, the full implications of such embedding have not yet been adequately incorporated into modern thinking. Nonetheless, several authors have made interesting contributions elaborating on Heidegger's insights. Taylor, for instance, extensively developed the implications of this for meaningfulness in the context of ethics. ${ }^{13}$ Aiming to retrieve the idea of a horizon, he meticulously articulated an ethical horizon. He likewise hinted at what could be called a natural horizon (making space for our embeddedness in nature) and a social horizon (indicating our 3D embedding in the social world) as possible articulations for such a notion. Again, for these horizons to regain their full meaning, their perception should go beyond the merely cognitive. A meaningful relation towards the world is not about the disclosure of knowledge but about brief manifestations of something evocative that recedes almost the moment it appears, transforming the experience into a subtly enhanced understanding - which is not the same as objective knowledge.

The following two descriptions aim to illustrate the implications of the recognition of a wider horizon. In the first situation, the horizon is fully ignored. In the second, the recognition of its existence is allowed to dawn. Both descriptions take the societal horizon as one possible articulation of the horizon. The shift from a 'flattened' view of the world to a 3D view constitutes a transformation that is fundamental to meaning because it makes for enhanced meaningfulness. Particular attention is paid to the importance of being situated and the process of shifting meaning.

${ }^{11}$ Cottingham, op cit., 17.

12 Charles Taylor, The Ethics of Authenticity (Cambridge, Massachusets, London: Harvard University Press, 1991), 69.

${ }^{13}$ See Taylor, Sources of the Self. 


\section{N. NOTE 143}

\section{From a Social World to a Social Horizon}

The notions 'social world' or 'social horizon' do not refer to the close circle of friends and family. They rather embrace society as a whole. Different perspectives of these notions are possible. Mainstream worldview and discourses encourage basic principles like efficiency. This is unwittingly conducive to instrumental and functional interaction between people. Society is taken to be something 'out there' made up of unknown people and depersonalised institutions. Exaggeratingly, people may take the services they receive from others for granted and perceive them as self-evidently at their disposal to pursue their own goals. Those who adopt such a stance, engage in a one-way relationship. The intentionality of the act flows from society towards the individual. The individual tries to 'gain' something from society and attempts to have society do something for them. They will feel no obligation or responsibility towards society for they think of it in dehumanised terms. Cultural embedding and the horizon aspects are incongruous things to them. They are incapable to grasp in depth the historical dimension of society, failing to acknowledge the previous generations of people that have helped give shape to today's society. They rather perceive society as a construction in terms of the here and now. This kind of perception towards society can be called 'flattened' and one-dimensional

Besides this instrumental and functional view of society, there is the possibility of people widening their perspective. As a matter of fact, in these days a growing awareness of this horizon can be discerned. Policy-makers and other people in the political arena have begun to recognise the relation between awareness of a societal horizon, social cohesion and an increase in well-being. That is why Belgium, to give but one example, aims to enable people to have the kind of experiences that may foster such recognition. Examples are government-sponsored local community breakfasts or annual barbecue parties in the central square of a village or town. The relevance of such events is not so much that they can create a different atmosphere, but rather that they satisfy the minimum condition for 'openness' towards the community or society. Individuals with an instrumental outlook, i.e. those who take their community and other people's services for granted, are likely to go through a kind of experience that is very much unlike what they are used to. The intentionality of the experience has another flavour-another meaning-even if still flowing towards the individual. Their usual notion of 'self-evidently obtaining' something from society may well start to make room for a sense of non-intentional 'receiving'. The moment this inversion in intentionality is sensed is crucial. It creates a feeling of belonging, of being part of, of being situated. This can open the door for people to discover greater depths in their relationship with the social environment. When this shift in meaning happens, they can recognise their embeddedness in a social horizon (a 3D dimension).

Such an initial opening - up may be followed by similar experiences, allowing the individuals concerned to start to grasp the social and historical 
dimensions of life, as well as the intensity and the enhanced meaningfulness this may bring about. A changed perception-a significant change in meaning-can happen on an implicit or on an explicit level, while the meaningfulness is further enhanced by subsequent reflection.

The notion of enhanced meaningfulness does not fit in readily with the currently well-established discourse of personal preferences and choices. Nor is it related to the subject-object ontology that is still prevailing over other views. Prior to a more detailed analysis of the transition in meaning that accompanies this shift from non-recognition to recognition, it may therefore be interesting to try and obtain a fuller understanding of what this transition does to an individual, in terms of their awareness of being situated in this horizon. Subsequently, the structure of the shift in meaning can be analysed so as to make clear why it can be considered a successful shift.

\section{The Inarticulate Awareness of Situatedness}

While people's initial dim recognition of 'receiving' will not substantially change their ways of acting and experiencing, its effect may increase with further experiences of a similar nature. An important outcome may be a sense of embeddedness or situatedness. One author whose ideas help explain this notion, which, after all, is hardly self-evident, is Heidegger. Scrutinising the notion of being-in-the-world, Heidegger described the fundamental difference between the ways people relate to their surrounding space, and the way that things do. According to him, because of people's Dasein, they are inherently in search of a sense of familiarity with this space. They experience it as an enveloping world rather than as empty space. Heidegger exemplified this sense of familiarity by way of a step by step analysis of people's encounters with the surrounding objects. He did not describe these objects as 'things' people are looking at (and which is not the way they perceive them anyway) but as useful things. These useful things are by nature something in order to, they always contain a reference of something to something. Heidegger gave the example of how a pen refers to ink, to paper, to desk, to furniture, to room. He insisted that people do not perceive these 'things' one by one, that they do not simply add them up to an entire space. Rather, "what people experience as nearest to them, although they do not grasp it thematically, is the room itself. This is not what is 'between the four walls' in a geometrical, spatial sense, but rather a[s ] material for living." 14

Heidegger then proceeded to discuss the specific example of a hammer as a 'useful thing' and its unarticulated meaning. This quality of 'being there in order to' gives the hammer a kind of familiarity. When people use it for hammering, its handiness is revealed ${ }^{15}$, its 'being-in-itself, which is different from merely occurring. This handiness is not apparent from its

\footnotetext{
${ }^{14}$ Ibid., 64.

15 "Handiness is the ontological categorical definition of beings as they are in themselves'." Ibid., 67.
} 


\section{N. NOTE 145}

outward appearance. People cannot discover it by merely looking at it. They cannot find out the handiness of useful things through any theorising by way of their objectifying capacity. The only way to find this out is by actually using them, and the only way to know that they are useful is through association. Because people see useful things and associate them with their handiness to themselves, the result is a multitude of references of the type of 'in-order-to'. Heidegger called this kind of perception circumspection (Umsicht, or 'lookingabout'). ${ }^{16}$

Access to the handiness of a useful thing may seem self-evident, but this is not so. One characteristic is that the useful thing is hardly present at all when being used. It withdraws. For example, while hammering, people do not concentrate on the hammer itself, but on what it is being used for. People focus on the work they have to finish, on the production. The activity holds the totality of references in which useful things are encountered. Hence, the 'what-for' is first and foremost. There is yet another reason why access is not self-evident. People recognise the handiness the moment the useful thing, the hammer, becomes unusable. This happens when "the constitutive reference of the in-order-to to a what-for has been disturbed." 17 The wider context of the useful thing (the hammer referring to the nail, to the impossibility of finishing the work, and to the work) then becomes apparent. This is not something never recognised before but a totality that was included in our circumspection from the very beginning.

However, this disturbance causes the hammer to be thematised and objectively present through people's cognitive capacity. Its 'practical' behaviour is transformed to 'theoretical' behaviour and the enchantment of interiorisation is broken. Theoretical observation of the thing makes it impossible to have adequate access to its handiness. People can never gain conscious access to the interiorised meaning of things.

What is the relevance of this to situatedness in a social horizon? Contrary to the prevailing ideas of meaning as a subjective condition of wellbeing based on personal preferences and choices, Heidegger showed that man's Dasein (being there) is ontically constituted by being-in-the-world. People exist as being-in-the-world. When they are able to make the transition from a onedimensional view of the social world to the 3D concept of a social horizon (as a 'result' of experiences of receiving), this horizon briefly lights up again. It becomes apparent again, in an unarticulated manner. Similarly to the situation of the hammer and the room, in a very literal sense people become aware of a part of reality they had not noticed before. There is, as it were, 'more world' with meaning. It is as if they suddenly become aware of the room-the horizons-they have been working in, not in any theoretical way of conceptualising the four walls, its floor and ceiling. People become aware of its spatial presence and of their having been in it all this time. It will place their life in a different, broader perspective. Yet, more space having meaning is not

$$
\begin{aligned}
& { }^{16} \mathrm{Ibid} . \\
& { }^{17} \mathrm{Ibid} ., 70 .
\end{aligned}
$$




\section{REFLECTIONS ON MEANINGFULNESS}

the only reason why there is meaningfulness. Becoming aware of being bound up to this horizon, and always having been so (rather than perceiving themselves as detached), is at the same time an affirmation, it is an affirmation of the right to be in this space. This affirmation does not function on the level of the ego, but rather on the existential level.

The social horizon is only accessible because it lights up in 'thinking', as a condition for existence. However, it does not light up in the same way as the quality of a useful thing does, i.e. at a moment of a disturbed relation. It lights up precisely because it touches. Hence both 'processes'- disturbance and being touched by something - centre on the same kind of shift in meaning.

If the implicit recognition of the horizons warrants increased meaningfulness, the reverse-flattened awareness-should come with decreased meaningfulness. This seems true. As pointed out, if people have a flattened worldview, if they are cut off from this wider horizon and if they relate to the world only in instrumental terms, the result will be a loss of meaning. These 'facts' have been studied in other disciplines as well. One psychological reason for decreased meaning appears to be fear-collective fear. In current society, the fear to enter the world, literally, decreases meaning. British research commissioned by the Children's Society and Frank Ferudi ${ }^{18}$ have shown that in 1970 a child aged about eight could wander up to about 840 metres from their home. In 1997 this was reduced to 280 metres, and in 2007 to 20 metres. Parents will allow their children to play in the garden of their own home, but not beyond. The main reason for this spatial isolation is that the parents fear their children may fall victim to traffic accidents, but even more so, that they may be kidnapped. People nowadays have far less confidence in their neighbours and in people in general, even though this is not borne out by statistics.

People's relationship with their social world has drastically changed, but the same can be said of the relationship with nature. ${ }^{19}$ In a literal sense, young people are deprived of the opportunity to have meaningful encounters with the world, including nature, to be touched by it, to sense the interrelated meanings of things. Direct physical contact is taught to be avoided. Intimacy with the world is gone. Consequently, the impact of fear on their sense of meaningfulness is substantial. Only without fear can they fully recognise this horizon and continue to be a part of it-as Cottingham puts it, to feel 'at home' in it. It is thus that a basic layer of broader meaningfulness can be created.

\footnotetext{
${ }^{18}$ Frank Ferudi, Paranoid Parenting, (Allen Lane, Penguin, 2001.)

19 See for example the 2008 bestseller Louv, R., Last Child in the Woods' Saving our children from Nature-deficit disorder (Chapel Hill: Algonguin Paperbacks, 2008).
} 
N. NOTE 147

\section{How Can the Shift from Non-Recognition to Recognition of the Horizon be Successful?}

So far, the recognition of the broader horizon and a sense of enhanced meaningfulness have been associated with each other, because they were supposed to further the sense of situatedness and affirmation. As mentioned; the act of recognising is not merely cognitive. It rather refers to the broader faculties of relating and understanding, of which the cognitive activity is only a part. Here, 'recognising' and 'being aware' also refer to the susceptibility to being touched. This final part of this article analyses why being touched-or being appealed-is so important for meaningfulness. The outcome may be that this experience can be said to drive a successful shift from a nonrecognition to a recognition of the horizon.

As said, Heidegger believed that the underlying, interiorised meaning of the world and its elements, such as a tool, can light up when their use is disturbed or obstructed. In the case of the horizon, it was suggested that it is not only a disturbance that is involved. People can also get touched. Both seemingly contradictory elements are at the heart of meaning and its increase as well as its decrease. How can an experience of being touched successfully lead to meaningfulness? This is not so evident as it may seem. For all somebody's willingness to recognise the horizons as depicted above, with one simple cognitive 'click' they can likewise decide to consider them meaningless, theoretical spielerei. Indeed, if they place themselves, their activities, their surrounding world in an ever-widening context, there comes a moment that they run the risk of losing meaning. Hence, a sentence like 'situatedness is a core element of meaningfulness', can be broken down into questions such as: 'to what extent do people need to be situated'; 'what's the point if all people are going to die anyway?' The analyses by Nagel and Nozick ${ }^{20}$ show that something felt to be meaningful in a particular, limited context may lose its appeal in a different, broader context. Nozick in particular has made clear that the underlying orientation of people's desire to live a meaningful life is usually towards infinity. No a priori assumptions can be made about any limits to the process of ever-widening situatedness or recontextualisation. Here the key elements of a successful shift come into the picture, because although the desire for meaning seems directed at the infinite, it must necessarily be reconciled with the finite. If it were not, the lives of people would eventually be futile and void of meaning. The question then is how and at what particular moment in the process this desire towards infinity should stop. At what point should it be reconciled with the finite? Nagel's answer is that everybody will have to decide for themselves where to draw the line, i.e. 'to begin and end somewhere in the middle of things'. Nagel means to say that the current worldview is inclined to give credit to theoretical behaviour, i.e. the external perspective or cognitive objectifying capacity, at the expense of the internal

${ }^{20}$ See Thomas Nagel, The View from Nowhere (USA: Oxford University Press, 1989) and Robert Nozick, The Examined Life (New York: touchstone, Simon \& Schluster, 1989). 


\section{8}

\section{REFLECTIONS ON MEANINGFULNESS}

perspective. It will always remain possible for valuable projects to be looked upon as arbitrary. However, this should not-or no longer-be overstressed. The external perspective is not decisive itself but it is allowed to be so by people. It can be changed when the way it is viewed is changed. It is therefore up to people to reconsider its influence and readjust it, if appropriate, to steer its successful outcome.

Nagel's answer, for all its sound argumentation, strikes as unsatisfactory, because it implies that the process of meaningfulness ultimately comes down to mere individual choice. Although Nagel has a point, it is only part of the story. Arnold Burms ${ }^{21}$ provides an alternative approach to the subject based on an analysis of the aesthetical experience. Burms highlights two aspects of this experience. First he observes that people's appreciation of a work of art that touches them is essentially characterised by a degree of passivity. People are touched, appealed or moved by something that they are impressed by and that they look up to in admiration. The second aspect is the phenomenon that an appealing work of art is evocative. A touching piece of art calls up something that seems to defy full articulation. A work of art that touches far exceeds its material presence. If people look at such a painting as Van Gogh's 'A pair of shoes', they will understand that the details signify something that they can never fully utter. They cannot deduce their significance by analysing the form and colours of the painting. The more they reflect on the work of art, the more its touching quality escapes its tangible reality. Yet, in order to experience its broader meaning, its concrete presence is indispensable. Its material reality and ungraspable meaning are inherently interconnected. The more a work of art touches, the more it seems to connect to something inarticulate and the stronger it will draw people's attention to itself and to its own concrete existence. ${ }^{22}$

This insight can be applied to the conception of the social horizon. Meaningfulness through recognition of the social horizon has initially been created by a shift in meaning. This is a shift from non-recognition to recognition of a 3D perspective. Phenomenologically, this leads to a broader world in almost a literal sense, and likewise to a broader based meaningfulness. However, as said, there is also the possibility of shifts leading to a sense of meaninglessness when re-contextualisation is placed in too broad a perspective. So why can it said to be successful? Two core elements of meaningfulness converge. First, recognition of the horizons occurs outside the cognitive faculty but is triggered by an experience of being touched by them. It is not a matter of inventing but of rediscovering. The evocative element of being touched enables never-ending shifts in meaning - the desire of meaning is directed at the infinite-while it is reconciled with the finite- the horizon. Like the work of art, the notion of 'horizon' has a kind of finiteness. The term 'a kind of' is to be taken literally, for the horizon is not so tangible as

\footnotetext{
21 Arnold Burms, "Humanisme en Ervaring van Zin," in G. Van Der Wal \& F. Jacogs eds., V ragen naar zin. Beschouwingen over zingevingsproblematiek (Baarn: Ambo, 1992).

22 Ibid., 63.
} 


\section{N. NOTE 149}

a work of art. Yet it allows a sufficient degree of conceptualisation for it to be finite. The shift is successful because it strikes as valuable both in its tangible limitations and in its connection to the infinite possibilities of recontextualisation.

Center Leo Apostel, Vrije Universiteit Brussel, Belgium

\section{References}

Burms, A., "Humanisme en ervaring van zin", in Van Der Wal, G. \& Jacobs, F. Eds., V ragen naar zin. Beschouningen over zingevingsproblematiek (Baarn: Ambo, 1992).

Cottingham, J., On the Meaning of Life (London: Routlegde, 2003).

Ferudi, F., Paranoid Parenting (Allen Lane, Penguin, 2001).

Heidegger, M., Being and Time, trans. by .Joan Stambaugh (Albany: State University of New York Press, 1996).

Klemke E. D. and Steven M. Cahn, The meaning of life. A Reader (USA: Oxford University Press, 2008).

Kymlicka, W., Contemporary Political Philosophy. An introduction (Oxford: Oxford University Press, 2002).

Mill, J. S., On Liberty (London: Longman, Roberts \& Green, 1869).

Nagel, T., The View from Nowhere (USA: Oxford University Press, 1989).

Nozick, R., The Examined Life (New York: Touchstone, Simon \& Schuster, 1989)

Philosophical Papers, 34:3 (2005).

Taylor, C., Sources of the Self. The Making of Modern Identity (Cambridge: Cambridge University Press, 1989)

, The Ethics of Authenticity. (Cambridge, Massachusets; London, England.: Harvard University Press, 1991).

The Monist, 93:1(2010).

Wolf, S., "Happiness and meaning. Two aspects of the Good Life," in Social Philosophy and Policy, 14:1 (1997), 207-225.

"Meaning and Morality," in Proceedings of the Aristotelian Society,

XCVII (1997), 299-315. 